Audiology

Neurotology
Audiol Neurotol 2019;24:109-116

DOI: $10.1159 / 000500658$
Received: December 11, 2018

Accepted after revision: April 29, 2019

Published online: July 17, 2019

\title{
Fluctuating Sensorineural Hearing Loss
}

\author{
Hui Liu ${ }^{a}$ Kunpeng Zhou ${ }^{a}$ Xuemei Zhang ${ }^{a}$ Kevin A. Peng ${ }^{b}$ \\ a First Hospital of Shijiazhuang City, Shijiazhuang City, China; ${ }^{b}$ House Clinic and House Ear Institute, \\ Los Angeles, CA, USA
}

\section{Keywords}

Fluctuating hearing loss · Ménière's disease .

Endolymphatic hydrops - Autoimmune inner ear disease .

Enlarged vestibular aqueduct

\begin{abstract}
Background: Several otologic conditions can present with fluctuating sensorineural hearing loss, including Ménière's disease, autoimmune inner ear disease, and enlarged vestibular aqueduct. Although these 3 etiologies vary greatly, distinguishing between these conditions at initial presentation can be challenging. Furthermore, initial treatment of these conditions is often similar. In this review, we discuss historical and current perspectives on diagnosis and treatment of these conditions. Summary: A literature search was performed regarding fluctuating hearing loss, and current treatment of these etiologies of fluctuating hearing loss was summarized. Immediate measures at the onset of acute hearing loss include corticosteroid therapy, while preventative and chronic therapies, which can limit disease severity and frequency, vary based on the specific condition treated. Key Messages: Fluctuating hearing loss can represent a range of pathologies, but the precise etiology may not be clear at initial presentation. Timely treatment and longterm follow-up, along with appropriate diagnostics, are necessary to optimize long-term hearing.
\end{abstract}

(c) 2019 S. Karger AG, Basel
๑ 2019 S. Karger AG, Basel

\section{Introduction}

Sensorineural hearing loss (SNHL) is a common clinical disorder characterized by elevated bone conduction thresholds on formal audiometric testing. Various classifications for SNHL have been proposed, and Schucknecht's [1993] classic description includes sensory, neural, strial, and cochlear conductive types. This classification notably omits fluctuating SNHL, which is often encountered clinically. Fluctuating SNHL presents as a single episode of SNHL, which is often acute in nature, followed by objective changes in hearing thresholds. The presence of these changes suggests a diagnosis of fluctuating SNHL.

More broadly, fluctuating hearing loss in both the pediatric and the adult population can result from a variety of etiologies. A perilymphatic fistula, which can be present congenitally or arise following trauma, often causes fluctuations in hearing [Grundfast and Bluestone, 1978]. An additional congenital etiology is the enlarged vestibular aqueduct syndrome (EVA). Infectious etiologies include cytomegalovirus infection and syphilis [Fowler et al., 1997]. Ménière's syndrome is deemed to be an idiopathic etiology, although inflammation likely plays a significant role in its pathogenesis. Other inflammatory etiologies include autoimmune inner ear disease (AIED) and Cogan's syndrome [Migliori et al., 2009]. Toxic etiologies include ototoxicity from systemic medications

\section{KARGER}

E-Mail karger@karger.com

www.karger.com/aud
Hui Liu, MD

First Hospital of Shijiazhuang City

Changan Qu, Fanxi Road 36

Shijiazhuang City, Hebei 050041 (China)

E-Mail sjzsdyyylh@163.com 
[Yorgason et al., 2006]. Neoplastic etiologies include endolymphatic sac tumor and even vestibular schwannoma, although the latter is typically associated only with hearing decline and not hearing fluctuations [Cmejrek and Megerian, 2004]. This review will focus on 3 specific etiologies: Ménière's disease (MD), AIED, and EVA.

The most common cause of fluctuating SNHL is MD, which is idiopathic in nature [Shea and Bowers, 1975]. An immune-mediated phenomenon is AIED. Genetic causes have also been implicated; EVA, for example, is associated with mutations in SLC26A4, resulting in the Pendred syndrome, which can present with progressive and/or fluctuating hearing loss [Everett et al., 2001]. In EVA, fluctuating SNHL is associated with pathological changes in the membranous labyrinth and dysfunction of the microcirculation [Okumura et al., 1995].

The clinical diagnoses underlying fluctuating hearing loss can demonstrate significant overlap, particularly in the early stages of presentation. In some patients with fluctuating hearing loss, hearing loss may improve spontaneously. However, intervention, either medical, surgical, or both, may be warranted. In this review, we present the potential etiologies of fluctuating hearing loss and discuss options for treatment.

\section{Methods}

PubMed, Europe PMC, and Google Scholar searches were conducted using the following search terms: "Ménière's disease," "fluctuating hearing loss," "enlarged vestibular aqueduct," "large vestibular aqueduct," and "autoimmune hearing loss." Articles discussing treatment of these conditions were selected for full-text review, which was performed by all authors. Due to the heterogeneity of data presented, a meta-analysis was not performed. Rather, findings were summarized in qualitative format.

\section{Results}

\section{MD and Cochlear Hydrops}

The most common diagnosis in patients [Lopez-Escamez et al., 2015] with fluctuating SNHL is MD [Shea and Bowers, 1975], which was first described by Prosper Ménière in 1861. It is characterized by episodes of vertigo, hearing loss, and tinnitus and/or aural fullness, and diagnosis relies on the exclusion of other causes [Committee on Hearing and Equilibrium, 1995; Lopez-Escamez et al., 2015]. Temporal bone histopathology has demonstrated a pathognomonic distension of the endolymphatic space termed endolymphatic hydrops [Hallpike and Cairns,
1938]. When vertigo is absent, the clinical presentation is termed cochlear hydrops [Glasscock and Miller, 1977].

The episodic symptomatology of MD has classically been explained by periodic ruptures in the already distended endolymphatic membranes. This results in disturbances in ion concentration in the endolymphatic and perilymphatic spaces, loss of the membrane potential, and resultant alterations in hearing and vestibular function, resulting in hearing loss and vertigo [Schuknecht et al., 1990]. More recently, however, it has been proposed that the histopathological changes observed with endolymphatic hydrops may not be directly responsible for the symptoms of MD but are rather a histological marker. This was suggested by a series of cases where histopathological findings and patient symptoms demonstrated little correlation [Merchant et al., 2005].

MD remains an idiopathic process, but potential etiologies, including viral infection or reactivation, autoimmune disorders, and changes in microvascular circulation, have been proposed [Mancini et al., 2002]. Histologically, $\mathrm{MD}$ is characterized by thickening of the basement membrane of the vestibular end organs; monolayer degeneration; and varying degrees of hair cell vacuolization, loss of stereocilia, formation of microvesicles in supporting cells, and stromal perivascular basement membrane thickening [McCall et al., 2009]. These changes may be secondary to cochlear ischemia, particularly in the stria vascularis, with resultant basement membrane thickening, fibrosis, and hair cell degeneration.

Edema in the cochlear duct may precede edema in the vestibular end organs, and fluctuations in edema in the cochlea as well as the vestibular end organs lead to fluctuating symptoms. Aquaporin dysfunction, which has been shown to cause impaired hearing in the setting of a morphologically normal cochlea in a mouse model, can cause basement membrane swelling, hair cell dysfunction, and hearing loss, and may also play a role in $\mathrm{MD}[\mathrm{Li}$ and Verkman, 2001].

The glycerol or mannitol dehydration test, electrocochleography, and videonystagmography have all been utilized in the diagnosis of MD. In the dehydration test, administration of glycerol or mannitol causes a decrease in intralabyrinthine pressure and a transient improvement in hearing [Klockhoff and Lindblom, 1966]. Electrocochleography may reveal an elevated summating potential/action potential ratio in MD, deemed secondary to the presence of endolymphatic hydrops [Gibson et al., 1977]. Videonystagmography reveals diminished peripheral vestibular function in the ear affected by $\mathrm{MD}$, although testing during an acute episode of vertigo may 
reveal an excitatory response [Sajjadi and Paparella, 2008]. More recent improvements in imaging technology, particularly of magnetic resonance imaging (MRI), have led to MRI emerging as a valuable diagnostic tool in MD. The relationship between MD symptomatology and membranous labyrinth edema as seen on MRI has recently been elucidated [Nakashima et al., 2007; Liu et al., 2008]. Using gadolinium-enhanced MRI and a 3-dimensional analysis protocol, labyrinthine edema and increased fluid was correlated with the degree of hearing impairment [Sepahdari et al., 2015].

\section{Enlarged Vestibular Aqueduct}

Another cause of fluctuating hearing loss is EVA, which commonly occurs in conjunction with the Pendred syndrome [Reardon et al., 2000]. Hearing loss is variable and most commonly affects high frequencies at initial presentation; later, hearing loss across all frequencies is commonly seen [Levenson et al., 1989]. Hearing loss is typically diagnosed in childhood, and worsening hearing thresholds have been associated with closed head trauma, strenuous exercise, and upper respiratory infections. A recent metaanalysis revealed that decreased hearing after minor head trauma was reported in roughly one-third of patients with EVA [Noordman et al., 2015]. The classic radiographic description, by Valvassori and Clemis [1978], is an enlargement of the vestibular aqueduct $>1.5 \mathrm{~mm}$ in diameter. The newer Cincinnati criteria define EVA as a diameter $\geq 1.0$ $\mathrm{mm}$ at the midpoint or $2.0 \mathrm{~mm}$ at the operculum [Boston et al., 2007]. Cross-sectional imaging, including computed tomography and MRI, is the gold standard for diagnosis [Hirsch et al., 1992; Okamoto et al., 1997].

EVA commonly presents with stepwise, progressive hearing loss, but hearing fluctuations can also occur [Ito et al., 2014]. The mechanism of these hearing fluctuations in EVA is not clear. Proposed etiologies have included changes in intracranial pressure causing pressure changes within the inner ear. Similar to MD, this can cause microruptures in the membranous labyrinth, leading to disruption in the endolymphatic and the perilymphatic composition and the electrochemical gradient [Jackler and De La Cruz, 1989].

The genetic etiology of EVA has been identified as SLC26A4, which encodes pendrin, an anion exchange protein [Everett et al., 2001]. In a rat model, loss of expression led to enlargement of the endolymphatic sac, with consequences on hearing and vestibular function. Associated abnormalities include blood vessel degeneration and pigmentary abnormalities [Wangemann et al., 2004; Albert et al., 2006].

Fluctuating Sensorineural Hearing Loss

\section{Autoimmune Inner Ear Disease}

A third condition presenting with fluctuating hearing loss is AIED [McCabe, 1979; Harris and Sharp, 1990]. AIED has been associated with systemic autoimmune conditions and viral infections, yet a significant proportion of patients lack systemic manifestations [Hughes et al., 1988]. Antigen-antibody interactions in the inner ear have long since been described [Lehnhardt, 1958]. These can lead to the development of bilateral hearing loss, and AIED is characterized by rapid progression of the hearing loss. Bilateral involvement is estimated to exceed $80 \%$ of cases [Girasoli et al., 2018]. This can fluctuate both early and late in the disease; spontaneous regression has also been described [Moscicki et al., 1994]. Viral etiologies, including associations with cytomegalovirus, herpes zoster, herpes simplex type I, influenza type B, and mumps, have been implicated [Merchant et al., 2008]. A seminal paper investigating the antibody profile of both human subjects and an animal model of experimental autoimmune SNHL demonstrated an autoantibody reactive to a $68-\mathrm{kD}$ inner ear antigen [Harris and Sharp, 1990].

On a related note, the immune system has been implicated in hearing loss separate from AIED. For example, patients with sudden low-frequency hearing loss demonstrate low serum concentrations of CD4- and CD8-positive lymphocytes compared to normal controls [GarciaBerrocal et al., 2006]. Monocytes and macrophages are the primary actors, and the inflammatory cascade causes an immune response resulting in potential tissue damage [Wynn et al., 2013]. Human immunodeficiency virus infection in young adults (age 18-35 years) has been associated with an increased risk of sudden hearing loss, an observation that hints at the potential effects of the immune system on hearing [Assuiti et al., 2013; Burdo et al., 2013; Lin et al., 2013].

\section{Treatment of $M D$}

Although treatment of fluctuating hearing loss varies based on the specific etiology, strategies and medications demonstrate significant overlap. Initial treatment of MD includes medical measures such as a low-salt diet, diuretics, and betahistine. Ultimately, however, the natural history of MD is progressive stabilization of hearing [Herraiz et al., 2006], and, therefore, the consequence of any active MD treatment on the final hearing outcome is controversial [Grant and Welling, 1997; Kinney et al., 1997; Fisher et al., 2012]. Just the same, some research suggests that timely MD therapy can lead to better long-term hearing [Tokumasu et al., 1995; Wu and Minor, 2003]. This is likely secondary to the observation that patients with MD

Audiol Neurotol 2019;24:109-116 111 
demonstrate pathological, structural changes not only in the cochlea (e.g., cochlear edema) but also in the auditory nerve. Because of this, early pharmacologic therapy may be beneficial for long-term hearing outcomes [Paparella et al., 1982; Megerian, 2005].

Treatment of MD can be stratified into medical and surgical therapies as well as nonablative versus ablative therapies. Medical nonablative therapies include lifestyle modification with a low-salt diet, diuretic therapy, corticosteroid therapy (including intratympanic administration), and betahistine. Medical ablative therapies include intratympanic gentamicin injection. Surgical nonablative therapies include endolymphatic sac decompression and the endolymphatic-mastoid shunt, while surgical ablative therapies include vestibular nerve section and labyrinthectomy.

Diuretic therapy in MD is aimed at reducing intralabyrinthine pressure, analogous to the effects of the glycerol test [Klockhoff et al., 1974]. Various regimens have been proposed, including acetazolamide, hydrochlorothiazide, and the combination of triamterene and hydrochlorothiazide. Acetazolamide likely has central effects that may ameliorate symptoms further [Foster, 2015].

Betahistine is a histamine receptor agonist that has been proven beneficial in the treatment of MD not only by limiting vertigo but also by improving hearing and stabilizing fluctuations. It acts as a vasodilator, causing increased blood flow to the cochlea, but its beneficial effects have also been attributed to inhibition of vestibular nuclei. It has been shown to be more effective than placebo [Lacour et al., 2007], and it is typically given at a dosage of $16 \mathrm{mg}$ twice or three times daily. Dosages up to $480 \mathrm{mg} /$ day have even been reported [Lezius et al., 2011]. In a more recent investigation, both low- and high-dose betahistines were noted to be no better than placebo at improving the symptoms of MD [Adrion et al., 2016].

Pressure equalization tube (PET) placement has been reported as MD treatment. The mechanism of benefit is unclear, but patients may undergo PET placement in preparation for the Meniett device (Medtronic Xomed, Jacksonville, Florida, USA). The Meniett device introduces low-pressure pulses through the tympanic membrane (via PET or, if present, an existing tympanic membrane perforation). In a recent study, both PET placement alone and PET placement with the Meniett device improved patient symptoms [Russo et al., 2017]. Recent meta-analyses of the Meniett device have reached differing conclusions, with 2 reviews supporting the use of the device [Ahsan et al., 2015; Zhang et al., 2016] and 1 review noting that the device had no benefit [Syed et al., 2015].
Ablative medical therapy in the treatment of MD notably consists of intratympanic gentamicin injection. Gentamicin is directly toxic to vestibular hair cells, dark cells of the stria vascularis, and the cristae ampullaris, and causes a decrease in endolymph production. In a metaanalysis, gentamicin therapy was found to be $96 \%$ effective in controlling vertigo when administered in a titrated fashion, with $82 \%$ achieving complete control of vertigo. Hearing loss was noted in 13-35\% of patients who underwent injection, with multiple doses daily associated with a greater degree of hearing loss [Chia et al., 2004]. However, some patients remain refractory to intratympanic gentamicin injections, and this has been hypothesized to be secondary to the robustness of the utricular macula to gentamicin toxicity in select patients [Ishiyama et al., 2007].

Surgical treatment in MD is reserved for patients with more severe symptoms. Surgical management may be divided into 2 main categories: first, nonablative operations aimed at changing the physiology of the disease, and, second, ablative operations aimed at removing the inner ear function and/or the nerve connection to the brain [Wiet et al., 1981; Konrad, 1986].

Nonablative surgical options most prominently include endolymphatic sac decompression/shunt in addition to the less-frequently performed semicircular canal plugging [Charpiot et al., 2010]. Endolymphatic sac decompression has been associated with postoperative improvement of hearing, which generally remains stable after surgery [Bretlau et al., 1989]. At the time of sac decompression, a silicone shunt maybe inserted into the mastoid, the so-called endolymphatic mastoid shunt. In a contrasting report, however, endolymphatic sac surgery demonstrated no significant hearing difference between MD patients who underwent surgery compared to a control group [Thomsen et al., 1981], which has been supported by additional research [Welling and Nagaraja, 2000]. Endolymphatic sac surgery may be more efficacious in treating vertigo symptoms, and decompression and shunt placement are generally regarded as being equally efficacious [Sood et al., 2014]. An argument for decompression over shunting is the theoretically decreased risk of meningitis with decompression and the possibility of worse hearing outcomes associated with shunt placement [Sood et al., 2014].

Destructive surgical options for MD include labyrinthectomy, which can be performed in either transmastoid or transcanal fashion [Cawthorne, 1957; Kemink et al., 1989]. Lateral semicircular canal plugging has also been described and can be effective at controlling rotatory ver- 
tigo [Charpiot et al., 2010]. Vestibular nerve section may also be performed, and surgical approaches include the middle fossa, retrolabyrinthine, retrosigmoid, and translabyrinthine approaches [Glasscock et al., 1980]. These can lead to durable resolution of vertigo, although profound hearing loss may be an unavoidable consequence depending on the approach used [Kemink et al., 1989; Teufert and Doherty, 2010].

Bilateral MD is estimated to occur in $10-25 \%$ of patients [House et al., 2006]. In patients with bilateral disease, nonablative therapies are preferred, as removal of bilateral peripheral function via ablative treatments, either medical or surgical, can lead to oscillopsia and permanent instability [Pyykko et al., 1994].

\section{Treatment of EVA}

Medical management of patients with EVA is primarily aimed at treating any sudden loss of hearing regardless of any association with trauma. Treatment with corticosteroids is generally accepted as beneficial. In one study, $80 \%$ of EVA patients treated with corticosteroids experienced hearing improvement, while only $20 \%$ of EVA patients not treated with corticosteroids improved spontaneously [Grimmer and Hedlund, 2007]. Other reports have suggested that steroid therapy does not change the natural course of the disease and does not decrease the volatility of patients' hearing.

The role of surgery in EVA is less clear. Endolymphatic sac surgery has been suggested as a technique to ameliorate hearing loss with variable success, including worse postoperative hearing in select cases [Jackler and De La Cruz, 1989; Welling et al., 1999].

Cochlear implantation (CI) may be entertained in patients with EVA who demonstrate profound hearing loss, particularly bilaterally. EVA patients demonstrate acceptable performance after CI [Au and Gibson, 1999; Miyamoto et al., 2002]. Curiously enough, however, fluctuating hearing in EVA patients following CI has also been described, with an incidence approximating 75\% [Lai and Shiao, 2004; Wu et al., 2008]. Potential causes include changes in endolymphatic fluid pressure leading to fluctuations in electrode impedance [Powell and Birman, 2015]. Given the potential for spontaneous improvement in hearing in EVA, the timing of implantation following progressive hearing loss is also a matter of debate. Only after stabilization of hearing should CI be considered [Chen et al., 2011]. Long-term data regarding CI in EVA suggest that a majority of patients achieve good hearing and speech recognition 5 years post-CI [Ko et al., 2013].

Fluctuating Sensorineural Hearing Loss

\section{Treatment of AIED}

Corticosteroids are commonly used for hearing fluctuations in patients with AIED. The standard dosage is $1 \mathrm{mg} / \mathrm{kg} /$ day or $60 \mathrm{mg} /$ day for at least 1 week, or until the hearing improves, followed by a taper [Rauch, 1997]. When treating AIED, corticosteroid therapy may last for weeks, if not longer [Niparko et al., 2005], although an average treatment duration of 4 weeks has been proposed [Loveman et al., 2004]. High-dose steroid pulse therapy has also been noted to be effective, although steroid side effects may limit long-term high-dose therapy in AIED [Alexander et al., 2009]. Common considerations with steroid therapy include exacerbation of preexisting diabetes or tuberculosis as well as gastrointestinal and neurological side effects. Avascular necrosis of the femoral head has also been described [Alexander et al., 2009].

Intratympanic injections for AIED may also be considered; these are typically performed on a weekly basis [Garcia-Berrocal et al., 2006]. Intratympanic injections have the benefit of minimizing systemic side effects of corticosteroid therapy, although their additional efficacy over oral steroids has not been proven. More targeted therapies for AIED include low-dose methotrexate, which has been associated with hearing improvement [Matteson et al., 2001]. However, in a randomized, double-blind, placebo-controlled trial, methotrexate was not found to maintain the hearing improvement achieved with prednisone therapy [Harris et al., 2003]. Azathioprine has also been suggested [Lasak et al., 2001]. Adalimumab and rituximab were studied in the treatment of AIED and demonstrated significant improvements in vertigo, tinnitus, and aural fullness, but not in hearing loss [Matsuo$\mathrm{ka}$ and Harris, 2013]. The use of immune modulators in AIED remains a subject of active research [Derebery et al., 2014].

\section{Discussion}

Fluctuating SNHL, defined as SNHL that fluctuates on serial audiometry and/or by subjective patient complaint, can represent a spectrum of conditions that may present similarly. A patient may first present with a single episode of sudden SNHL. On follow-up, hearing levels may improve and worsen; if this is the case, then fluctuating SNHL is diagnosed. Meanwhile, initial treatment of any sudden SNHL with corticosteroids is reasonable, and asymmetric sensorineural function should be evaluated with MRI. MRI can diagnose EVA, while MD and AIED are diagnosed primarily via history. 
Medical and surgical treatments depend on the severity of the disease and the specific pathophysiological process involved. Treatment of additional hearing loss subsequent to the initial episode includes further corticosteroid therapy, administered in either oral or intratympanic fashion. Surgical treatment may be considered for MD and includes nonablative and ablative procedures.

Over the course of follow-up, patients may progress to profound hearing loss in one or both ears in all 3 conditions: EVA, MD, and AIED. When this is the case, CI may provide significant benefit in hearing rehabilitation. Ultimately, a low threshold of suspicion for fluctuating SNHL is essential to ensure timely diagnosis and appropriate treatment.

\section{Statement of Ethics}

The authors have no ethical conflicts to disclose.

\section{Disclosure Statement}

The authors have no conflicts of interest to declare.

\section{Funding Sources}

The authors have no funding sources to declare.

\section{Author Contributions}

Drs. Liu and Zhou provided substantial contributions to the conception or design of the work. Drs. Zhang and Peng provided acquisition, analysis, and interpretation of the data for the work. Drs. Liu, Zhou, Zhang, and Peng drafted the work and revised it critically for important intellectual content, provided final approval of the version to be published, and agreed to be accountable for all aspects of the work in ensuring that questions related to the accuracy or integrity of any part of the work are appropriately investigated and resolved.

\section{References}

Adrion C, Fischer CS, Wagner J, Gürkov R, Mansmann U, Strupp M; BEMED Study Group. Efficacy and safety of betahistine treatment in patients with Meniere's disease: primary results of a long term, multicentre, double blind, randomised, placebo controlled, dose defining trial (BEMED trial). BMJ. 2016 Jan; 352:h6816.

Ahsan SF, Standring R, Wang Y. Systematic review and meta-analysis of Meniett therapy for Meniere's disease. Laryngoscope. 2015 Jan; 125(1):203-8.

Albert S, Blons H, Jonard L, Feldmann D, Chauvin $\mathrm{P}$, Loundon N, et al. SLC26A4 gene is frequently involved in nonsyndromic hearing impairment with enlarged vestibular aqueduct in Caucasian populations. Eur J Hum Genet. 2006 Jun;14(6):773-9.

Alexander TH, Weisman MH, Derebery JM, Espeland MA, Gantz BJ, Gulya AJ, et al. Safety of high-dose corticosteroids for the treatment of autoimmune inner ear disease. Otol Neurotol. 2009 Jun;30(4):443-8.

Assuiti LF, Lanzoni GM, Santos FC, Erdmann AL, Meirelles BH. Hearing loss in people with HIV/AIDS and associated factors: an integrative review. Braz J Otorhinolaryngol. 2013 Mar-Apr;79(2):248-55.

$\mathrm{Au}$ G, Gibson W. Cochlear implantation in children with large vestibular aqueduct syndrome. Am J Otol. 1999 Mar;20(2):183-6.

Boston M, Halsted M, Meinzen-Derr J, Bean J, Vijayasekaran S, Arjmand E, et al. The large vestibular aqueduct: a new definition based on audiologic and computed tomography correlation. Otolaryngol Head Neck Surg. 2007 Jun;136(6):972-7.
Bretlau P, Thomsen J, Tos M, Johnsen NJ. Placebo effect in surgery for Menière's disease: nineyear follow-up. Am J Otol. 1989 Jul;10(4): 259-61.

Burdo TH, Lackner A, Williams KC. Monocyte/ macrophages and their role in HIV neuropathogenesis. Immunol Rev. 2013 Jul;254(1): 102-13.

Cawthorne T. Membranous labyrinthectomy via the oval window for Menière's disease. J Laryngol Otol. 1957 Aug;71(8):524-7.

Charpiot A, Rohmer D, Gentine A. Lateral semicircular canal plugging in severe Ménière's disease: a clinical prospective study about 28 patients. Otol Neurotol. 2010 Feb;31(2):23740.

Chen X, Liu B, Liu S, Mo L, Liu H, Dong R, et al. The development of auditory skills in infants with isolated Large Vestibular Aqueduct Syndrome after cochlear implantation. Int J Pediatr Otorhinolaryngol. 2011 Jul;75(7):943-7.

Chia SH, Gamst AC, Anderson JP, Harris JP. Intratympanic gentamicin therapy for Ménière's disease: a meta-analysis. Otol Neurotol. 2004 Jul;25(4):544-52.

Cmejrek RC, Megerian CA. Obstructing lesions of the endolymphatic sac and duct mimicking Ménière's disease. Ear Nose Throat J. 2004 Nov;83(11):753-6.

Committee on Hearing and Equilibrium A-H. Committee on Hearing and Equilibrium guidelines for the diagnosis and evaluation of therapy in Menière's disease. American Academy of Otolaryngology-Head and Neck Foundation, Inc. Otolaryngol Head Neck Surg. 1995 Sep;113(3):181-5.
Derebery MJ, Fisher LM, Voelker CC, Calzada A. An open label study to evaluate the safety and efficacy of intratympanic golimumab therapy in patients with autoimmune inner ear disease. Otol Neurotol. 2014 Oct;35(9): 1515-21.

Everett LA, Belyantseva IA, Noben-Trauth K, Cantos R, Chen A, Thakkar SI, et al. Targeted disruption of mouse $\mathrm{Pds}$ provides insight about the inner-ear defects encountered in Pendred syndrome. Hum Mol Genet. 2001 Jan;10(2):153-61.

Fisher LM, Derebery MJ, Friedman RA. Oral steroid treatment for hearing improvement in Ménière's disease and endolymphatic hydrops. Otol Neurotol. 2012 Dec;33(9):168591.

Foster CA. Optimal management of Ménière's disease. Ther Clin Risk Manag. 2015 Feb;1: 301-7.

Fowler KB, McCollister FP, Dahle AJ, Boppana S, Britt WJ, Pass RF. Progressive and fluctuating sensorineural hearing loss in children with asymptomatic congenital cytomegalovirus infection. J Pediatr. 1997 Apr;130(4):624-30.

García-Berrocal JR, Ibáñez A, Rodríguez A, González-García JA, Verdaguer JM, Trinidad A, et al. Alternatives to systemic steroid therapy for refractory immune-mediated inner ear disease: A physiopathologic approach. Eur Arch Otorhinolaryngol. 2006 Nov; 263(11):977-82.

Gibson WP, Moffat DA, Ramsden RT. Clinical electrocochleography in the diagnosis and management of Meneère's disorder. Audiology. 1977 Sep-Oct;16(5):389-401. 
Girasoli L, Cazzador D, Padoan R, Nardello E, Felicetti M, Zanoletti E, et al. Update on Vertigo in Autoimmune Disorders, from Diagnosis to Treatment. J Immunol Res. 2018 Sep;2018: 5072582.

Glasscock ME 3rd, Hughes GB, Davis WE, Jackson CG. Labyrinthectomy versus middle fossa vestibular nerve section in Menière's disease. A critical evaluation of relief of vertigo. Ann Otol Rhinol Laryngol. 1980 Jul-Aug;89(4 Pt 1):318-24.

Glasscock ME 3rd, Miller GW. Diagnosis and management of cochlear hydrops. Laryngoscope. 1977 Feb;87(2):198-206.

Grant IL, Welling DB. The treatment of hearing loss in Meniere's disease. Otolaryngol Clin North Am. 1997 Dec;30(6):1123-44.

Grimmer JF, Hedlund G. Vestibular symptoms in children with enlarged vestibular aqueduct anomaly. Int $\mathrm{J}$ Pediatr Otorhinolaryngol. 2007 Feb;71(2):275-82.

Grundfast KM, Bluestone CD. Sudden or fluctuating hearing loss and vertigo in children due to perilymph fistula. Ann Otol Rhinol Laryngol. 1978 Nov-Dec;87(6 Pt 1):761-71.

Hallpike CS, Cairns H. Observations on the Pathology of Ménière's Syndrome: (Section of Otology). Proc R Soc Med. 1938 Sep;31(11): 1317-36.

Harris JP, Sharp PA. Inner ear autoantibodies in patients with rapidly progressive sensorineural hearing loss. Laryngoscope. 1990 May; 100(5):516-24.

Harris JP, Weisman MH, Derebery JM, Espeland MA, Gantz BJ, Gulya AJ, et al. Treatment of corticosteroid-responsive autoimmune inner ear disease with methotrexate: a randomized controlled trial. JAMA. 2003 Oct;290(14): 1875-83.

Herraiz C, Tapia MC, Plaza G. Tinnitus and Ménière's disease: characteristics and prognosis in a tinnitus clinic sample. Eur Arch Otorhinolaryngol. 2006 Jun;263(6):504-9.

Hirsch BE, Weissman JL, Curtin HD, Kamerer DB. Magnetic resonance imaging of the large vestibular aqueduct. Arch Otolaryngol Head Neck Surg. 1992 Oct;118(10):1124-7.

House JW, Doherty JK, Fisher LM, Derebery MJ, Berliner KI. Meniere's disease: prevalence of contralateral ear involvement. Otol Neurotol. 2006 Apr;27(3):355-61.

Hughes GB, Barna BP, Kinney SE, Calabrese LH, Nalepa NJ. Clinical diagnosis of immune inner-ear disease. Laryngoscope. 1988 Mar; 98(3):251-3.

Ishiyama G, Lopez I, Baloh RW, Ishiyama A. Histopathology of the vestibular end organs after intratympanic gentamicin failure for $\mathrm{Me}$ niere's disease. Acta Otolaryngol. 2007 Jan; 127(1):34-40.

Ito T, Li X, Kurima K, Choi BY, Wangemann P, Griffith AJ. Slc26a4-insufficiency causes fluctuating hearing loss and stria vascularis dysfunction. Neurobiol Dis. 2014 Jun;66:53-65.

Jackler RK, De La Cruz A. The large vestibular aqueduct syndrome. Laryngoscope. 1989 Dec;99(12):1238-42; discussion 1242-3.
Kemink JL, Telian SA, Graham MD, Joynt L. Transmastoid labyrinthectomy: reliable surgical management of vertigo. Otolaryngol Head Neck Surg. 1989 Jul;101(1):5-10.

Kinney SE, Sandridge SA, Newman CW. Longterm effects of Ménière's disease on hearing and quality of life. Am J Otol. 1997 Jan;18(1): 67-73.

Klockhoff I, Lindblom U. Glycerol test in Ménière's disease. Acta Otolaryngol. 1966 Jun; Suppl 224:449+.

Klockhoff I, Lindblom U, Stahle J. Diuretic treatment of Meniere disease. Long-term results with chlorthalidone. Arch Otolaryngol. 1974 Oct; 100(4):262-5.

Ko HC, Liu TC, Lee LA, Chao WC, Tsou YT, Ng $\mathrm{SH}$, et al. Timing of surgical intervention with cochlear implant in patients with large vestibular aqueduct syndrome. PLoS One. 2013 Nov;8(11):e81568.

Konrad HR. Intractable vertigo-when not to operate. Otolaryngol Head Neck Surg. 1986 Nov;95(4):482-4.

Lacour M, van de Heyning PH, Novotny M, Tighilet B. Betahistine in the treatment of Ménière's disease. Neuropsychiatr Dis Treat. 2007 Aug;3(4):429-40.

Lai CC, Shiao AS. Chronological changes of hearing in pediatric patients with large vestibular aqueduct syndrome. Laryngoscope. 2004 May;114(5):832-8.

Lasak JM, Sataloff RT, Hawkshaw M, Carey TE, Lyons KM, Spiegel JR: Autoimmune inner ear disease: steroid and cytotoxic drug therapy. Ear Nose Throat J. 2001 Nov;80(11):808-11, 815-6, 818 passim.

Lehnhardt E. [Sudden hearing disorders occurring simultaneously or successively on both sides]. Z Laryngol Rhinol Otol. 1958 Jan; 37(1):1-16.

Levenson MJ, Parisier SC, Jacobs M, Edelstein DR. The large vestibular aqueduct syndrome in children. A review of 12 cases and the description of a new clinical entity. Arch Otolaryngol Head Neck Surg. 1989 Jan;115(1): 54-8.

Lezius F, Adrion C, Mansmann U, Jahn K, Strupp M. High-dosage betahistine dihydrochloride between 288 and $480 \mathrm{mg} /$ day in patients with severe Menière's disease: a case series. Eur Arch Otorhinolaryngol. 2011 Aug;268(8): 1237-40.

Li J, Verkman AS. Impaired hearing in mice lacking aquaporin-4 water channels. J Biol Chem. 2001 Aug;276(33):31233-7.

Lin C, Lin SW, Weng SF, Lin YS. Increased risk of sudden sensorineural hearing loss in patients with human immunodeficiency virus aged 18 to 35 years: a population-based cohort study. JAMA Otolaryngol Head Neck Surg. 2013 Mar;139(3):251-5.

Liu F, Huang WN, Song HT, Zhang QY. [Endolymphatic visualization in patients with $\mathrm{Me}$ niere's disease]. Zhongguo Yi Xue Ke Xue Yuan Xue Bao. 2008 Dec;30(6):651-4.

Lopez-Escamez JA, Carey J, Chung WH, Goebel JA, Magnusson M, Mandalà M, et al.; Classi- fication Committee of the Barany Society; Japan Society for Equilibrium Research; European Academy of Otology and Neurotology (EAONO); Equilibrium Committee of the American Academy of Otolaryngology-Head and Neck Surgery (AAO-HNS); Korean Balance Society. Diagnostic criteria for Menière's disease. J Vestib Res. 2015;25(1):1-7.

Loveman DM, de Comarmond C, Cepero R, Baldwin DM. Autoimmune sensorineural hearing loss: clinical course and treatment outcome. Semin Arthritis Rheum. 2004 Oct; 34(2):538-43.

Mancini F, Catalani M, Carru M, Monti B. History of Meniere's disease and its clinical presentation. Otolaryngol Clin North Am. 2002 Jun;35(3):565-80.

Matsuoka AJ, Harris JP. Autoimmune inner ear disease: a retrospective review of forty-seven patients. Audiol Neurotol. 2013;18(4):22839.

Matteson EL, Fabry DA, Facer GW, Beatty CW, Driscoll CL, Strome SE, et al. Open trial of methotrexate as treatment for autoimmune hearing loss. Arthritis Rheum. 2001 Apr; 45(2): 146-50.

McCabe BF. Autoimmune sensorineural hearing loss. Ann Otol Rhinol Laryngol. 1979 SepOct;88(5 Pt 1):585-9.

McCall AA, Ishiyama GP, Lopez IA, Bhuta S, Vetter S, Ishiyama A. Histopathological and ultrastructural analysis of vestibular endorgans in Meniere's disease reveals basement membrane pathology. BMC Ear Nose Throat Disord. 2009 Jun;9(1):4.

Megerian CA. Diameter of the cochlear nerve in endolymphatic hydrops: implications for the etiology of hearing loss in Ménière's disease. Laryngoscope. 2005 Sep;115(9):1525-35.

Merchant SN, Adams JC, Nadol JB Jr. Pathophysiology of Meniere's syndrome: are symptoms caused by endolymphatic hydrops? Otol Neurotol. 2005 Jan;26(1):74-81.

Merchant SN, Durand ML, Adams JC. Sudden deafness: is it viral? ORL J Otorhinolaryngol Relat Spec. 2008;70(1):52-60; discussion 602.

Migliori G, Battisti E, Pari M, Vitelli N, Cingolani C. A shifty diagnosis: cogan's syndrome. A case report and review of the literature. Acta Otorhinolaryngol Ital. 2009 Apr;29(2):10813.

Miyamoto RT, Bichey BG, Wynne MK, Kirk KI. Cochlear implantation with large vestibular aqueduct syndrome. Laryngoscope. $2002 \mathrm{Jul}$ 112(7 Pt 1):1178-82.

Moscicki RA, San Martin JE, Quintero CH, Rauch SD, Nadol JB Jr, Bloch KJ. Serum antibody to inner ear proteins in patients with progressive hearing loss. Correlation with disease activity and response to corticosteroid treatment. JAMA. 1994 Aug;272(8):611-6.

Nakashima T, Naganawa S, Sugiura M, Teranishi $\mathrm{M}$, Sone M, Hayashi $\mathrm{H}$, et al. Visualization of endolymphatic hydrops in patients with $\mathrm{Me}$ niere's disease. Laryngoscope. 2007 Mar; 117(3):415-20. 
Niparko JK, Wang NY, Rauch SD, Russell GB, Espeland MA, Pierce JJ, et al.; AIED Study Group. Serial audiometry in a clinical trial of AIED treatment. Otol Neurotol. 2005 Sep; 26(5):908-17.

Noordman BJ, van Beeck Calkoen E, Witte B, Goverts T, Hensen E, Merkus P. Prognostic factors for sudden drops in hearing level after minor head injury in patients with an enlarged vestibular aqueduct: a meta-analysis. Otol Neurotol. 2015 Jan;36(1):4-11.

Okamoto K, Ito J, Furusawa T, Sakai K, Tokiguch S. Large vestibular aqueduct syndrome with high CT density and high MR signal intensity. AJNR Am J Neuroradiol. 1997 Mar; 18(3): $482-4$.

Okumura T, Takahashi H, Honjo I, Takagi A, Mitamura K. Sensorineural hearing loss in patients with large vestibular aqueduct. Laryngoscope. 1995 Mar;105(3 Pt 1):289-93; discussion 293-4.

Paparella MM, McDermott JC, de Sousa LC. Meniere's disease and the peak audiogram. Arch Otolaryngol. 1982 Sep;108(9):555-9.

Powell HR, Birman CS. Large vestibular aqueduct syndrome: impedance changes over time with different cochlear implant electrode arrays. Cochlear Implants Int. 2015;16(6):326-30.

Pyykkö I, Ishizaki H, Kaasinen S, Aalto H. Intratympanic gentamicin in bilateral Menière's disease. Otolaryngol Head Neck Surg. 1994 Feb;110(2):162-7.

Rauch SD. Clinical management of immune-mediated inner-ear disease. Ann N Y Acad Sci. 1997 Dec;830:203-10.

Reardon W, OMahoney CF, Trembath R, Jan H, Phelps PD. Enlarged vestibular aqueduct: a radiological marker of pendred syndrome, and mutation of the PDS gene. QJM. 2000 Feb;93(2):99-104.

Russo FY, Nguyen Y, De Seta D, Bouccara D, Sterkers O, Ferrary E, et al. Meniett device in meniere disease: Randomized, double-blind, placebo-controlled multicenter trial. Laryngoscope. $2017 \mathrm{Feb} ; 127(2): 470-5$.

Sajjadi H, Paparella MM. Meniere's disease. Lancet. 2008 Aug;372(9636):406-14.

Schuknecht H. Pathology of the ear. 2nd ed. Philadelphia: Lea \& Febiger; 1993. p. 273.

Schuknecht HF, Suzuka Y, Zimmermann C. Delayed endolymphatic hydrops and its relationship to Meniére's disease. Ann Otol Rhinol Laryngol. 1990 Nov;99(11):843-53.

Sepahdari AR, Ishiyama G, Vorasubin N, Peng KA, Linetsky M, Ishiyama A. Delayed intravenous contrast-enhanced 3D FLAIR MRI in Meniere's disease: correlation of quantitative measures of endolymphatic hydrops with hearing. Clin Imaging. 2015 Jan-Feb;39(1): 26-31.

Shea JJ Jr, Bowers RE. Diagnosis and treatment of fluctuant hearing loss. Otolaryngol Clin North Am. 1975 Jun;8(2):431-8.

Sood AJ, Lambert PR, Nguyen SA, Meyer TA. Endolymphatic sac surgery for Ménière's disease: a systematic review and meta-analysis. Otol Neurotol. 2014 Jul;35(6):1033-45.

Syed MI, Rutka JA, Hendry J, Browning GG. Positive pressure therapy for Meniere's syndrome/disease with a Meniett device: a systematic review of randomised controlled trials. Clin Otolaryngol. 2015 Jun;40(3):197-207.

Teufert KB, Doherty J. Endolymphatic sac shunt, labyrinthectomy, and vestibular nerve section in Meniere's disease. Otolaryngol Clin North Am. 2010 Oct;43(5):1091-111.

Thomsen J, Bretlau P, Tos M, Johnsen NJ. Ménière's disease: endolymphatic sac decompression compared with sham (placebo) decompression. Ann N Y Acad Sci. 1981;374(1): 820-30.

Tokumasu K, Fujino A, Yoshio S, Hoshino I. Prognosis of Menière's disease by conservative treatment: retrospective study on the time course of the disease. Acta Otolaryngol Suppl. $1995 ; 519: 216-8$.

Valvassori GE, Clemis JD. The large vestibular aqueduct syndrome. Laryngoscope. 1978 May; 88(5):723-8.

Wangemann P, Itza EM, Albrecht B, Wu T, Jabba SV, Maganti RJ, et al. Loss of KCNJ10 protein expression abolishes endocochlear potential and causes deafness in Pendred syndrome mouse model. BMC Med. 2004 Aug;2(1):30.

Welling DB, Nagaraja HN. Endolymphatic mastoid shunt: a reevaluation of efficacy. Otolaryngol Head Neck Surg. 2000 Mar;122(3):340-5.

Welling DB, Slater PW, Martyn MD, Antonelli PJ, Gantz BJ, Luxford WM, et al. Sensorineural hearing loss after occlusion of the enlarged vestibular aqueduct. Am J Otol. 1999 May; 20(3):338-43.

Wiet RJ, Kazan R, Shambaugh GE Jr. An holistic approach to Ménière's disease. Medical and surgical management. Laryngoscope. 1981 Oct;91(10):1647-56.

Wu CM, Sun YS, Liu TC. Long-term speech perception of cochlear implantation in children with large vestibular aqueduct syndrome: how we do it. Clin Otolaryngol. 2008 Oct; 33(5):472-5.

Wu IC, Minor LB. Long-term hearing outcome in patients receiving intratympanic gentamicin for Ménière's disease. Laryngoscope. 2003 May;113(5):815-20.

Wynn TA, Chawla A, Pollard JW. Macrophage biology in development, homeostasis and disease. Nature. 2013 Apr;496(7446):445-55.

Yorgason JG, Fayad JN, Kalinec F. Understanding drug ototoxicity: molecular insights for prevention and clinical management. Expert Opin Drug Saf. 2006 May;5(3):383-99.

Zhang SL, Leng Y, Liu B, Shi H, Lu M, Kong WJ. Meniett Therapy for Ménière's Disease: An Updated Meta-analysis. Otol Neurotol. 2016 Mar;37(3):290-8. 